\title{
Domenica De Falco, La Femme et les personnages féminins chez les Goncourt
}

\section{Maria Emanuela Raffi}

\section{Q OpenEdition}

1 Journals

\section{Edizione digitale}

URL: http://journals.openedition.org/studifrancesi/2237

DOI: 10.4000/studifrancesi.2237

ISSN: 2421-5856

\section{Editore}

Rosenberg \& Sellier

\section{Edizione cartacea}

Data di pubblicazione: 1 aprile 2014

Paginazione: 174-175

ISSN: 0039-2944

\section{Notizia bibliografica digitale}

Maria Emanuela Raffi, « Domenica De Falco, La Femme et les personnages féminins chez les Goncourt »,

Studi Francesi [Online], 172 (LVIII | I) | 2014, online dal 01 avril 2014, consultato il 18 septembre 2020.

URL : http://journals.openedition.org/studifrancesi/2237 ; DOI : https://doi.org/10.4000/studifrancesi. 2237

Questo documento è stato generato automaticamente il 18 settembre 2020.

\section{(c)}

Studi Francesi è distribuita con Licenza Creative Commons Attribuzione - Non commerciale - Non opere derivate 4.0 Internazionale. 


\title{
Domenica De Falco, La Femme et les personnages féminins chez les Goncourt
}

\author{
Maria Emanuela Raffi
}

\section{NOTIZIA}

DOMENICA DE FALCO, La Femme et les personnages féminins chez les Goncourt, Paris, Champion, 2012, pp. 328.

1 Uno studio sulla figura femminile nell'opera di due scrittori misogini quali i Goncourt non può riservare grandi sorprese; Domenica De Falco ha tuttavia il merito di percorrere in modo puntuale e approfondito tutte le sfumature di una concezione che non si mostra sempre compattamente univoca, «mais parcourue de failles, de paradoxes, de dénégations ponctuelles». Organizzato in tre parti - «Corps», «Parures», «Discours» -, il saggio parte dalla diffusa concezione negativa della donna nella seconda metà del xIX secolo, nella quale la «matérialité fonctionnelle» legata alla riproduzione $\mathrm{e}$ quindi alla natura (Michelet), costituisce la pietra miliare.

In questo contesto l'opera dei Goncourt fa spesso riferimento all'«animalité» féminine, ma anche ad un corpo femminile minato da malattie più o meno indefinite, talvolta legate ad una religiosità tutta emotiva e languida, con forti propensioni al masochismo o all'isteria. È il caso, lungamente analizzato dall'A., di Germinie Lacerteux, «crucifiée par son corps puisque celui-ci s'impose à son cerveau». L'altra modalità di degradazione della figura femminile presente nei romanzi dei Goncourt - e condivisa dalla letteratura della seconda metà dell'Ottocento - è la figura della prostituta, protagonista de La Fille Élisa, di cui la De Falco sottolinea lo specifico carattere messo in evidenza dai Goncourt, «la paresse», che si accompagna nel romanzo all'assenza di una vera e propria descrizione fisica e ad una sorta di alienazione che le sottrae anche un possibile ruolo sociale. 
3 Altro corpo femminile «offert au public» è quello dell'artista - acrobata, attrice, modella di pittore -, che nei romanzi dei Goncourt suscita la gelosia maschile, ma riesce a sottrarsi alla degradazione trasformandosi in «objet d'art».

4 L'estetizzazione come possibile via di salvezza della donna appare al centro della seconda parte del saggio, «Parures», dedicata alla trasformazione «de la mode vestimentaire» all'epoca e nei romanzi dei Goncourt. «Les Goncourt, - scrive l'A. historiens avant d'être romanciers, attribuent une importance extrême à "ce morceau de tissu" qui abrite, en l'habitant secrètement, le corps et l'âme de la femme. Le vêtement représente, pour eux, un document à part entière» e dell'abbigliamento vengono in questa parte indagate tutte le diverse declinazioni: valorizzanti (soprattutto in Chérie), degradanti (particolarmente in Germinie Lacerteux), volutamente assenti (in Madame Gervaisais in quanto possibile ostacolo alla prospettiva spiritualizzante) o imposte (le 'uniformi' di Sour Philomène e di La Faustin).

5 L'ultima parte - «Discours» -, è infine dedicata al ruolo della lingua e della parola femminili nell'opera dei Goncourt. La scarsità della comunicazione, come mostra l'A., ne è il tratto comune: «Si la femme n'est rien d'autre qu'un ensemble de phénomènes physiologiques, comment peut-elle parler?» Benché i Goncourt insistano nel Journal sul fatto che «la femme est 'naturellement' bavarde», il percorso dei loro personaggi femminili va per la De Falco «de la parole au silence» (Germinie Lacerteux), «du silence à l'aphasie» (La Fille Élisa), o approda alla "parole religieuse» che, perduta la sua funzione referenziale, si fa terapia per gli altri (Sœur Philomène) o "parole mystique» in Madame Gervaisais. In Renée Mauperin, tuttavia, è rappresentato un altro tipo di donna e di linguaggio femminile - la «jeune fille moderne» - destinata a perdere rapidamente le proprie caratteristiche e a 'femminilizzarsi' nel corso del romanzo, mentre un altro caso a parte è costituito per la De Falco dalle «femmes-artistes», che nel panorama femminile dei Goncourt impersonano l'arte della parola, del tutto alienata rispetto alla persona che le dà voce (La Faustin).

6 «L'animalisation de la parole», frutto di una rabbia trattenuta e verbalmente inespressa, alternata ad una vivace conversazione sociale formalmente incanalata costituisce infine l'aspetto singolare di Chérie, ormai alle soglie del romanzo decadente, mentre l'ultimo capitolo dello studio è dedicato al saggio dei Goncourt La femme au XVIII ${ }^{e}$ siècle, in cui campeggia la figura della principessa Matilde, verso la quale si canalizza per l'A. tutta la nostalgia dei Goncourt per la realtà del salon del XviII secolo, luogo idealizzato di conversazione elegante e colta, luogo in cui trionfava, per uomini e donne, l'esprit. 